\title{
STUDIES OF RIBOSE METABOLISM. I. THE PATHWAY OF NUCLEIC ACID RIBOSE SYNTHESIS IN A HUMAN CARCINOMA CELL IN TISSUE CULTURE ${ }^{1}$
}

\author{
By HOWARD H. HIATT \\ (From the Department of Medicine, Beth Israel Hospital, and Harvard Medical School, \\ Boston, Mass.)
}

(Submitted for publication March 1, 1957; accepted June 11, 1957)

An impressive body of evidence is available demonstrating the importance of the pentose phosphate pathway (hexose monophosphate shunt) in the intermediary metabolism of carbohydrate (1). The pathway is involved in a number of vital biological processes, including photosynthesis (2), carbohydrate utilization by many bacteria (3), the elaboration of the ribose moiety of nucleic acids in the chick (4), in certain microorganisms (5-8), and in the rat $(9,10)$, the synthesis of the precursor of aromatic amino acids (11), and the generation of reduced triphosphopyridine nucleotides, which are required for the synthesis of several substances including fatty acids and cholesterol (12). In addition, it is the route by which a substantial fraction of glucose is catabolized by rat liver slices (13). Recent work has demonstrated its role in the in vivo conversion of ribose and xylose carbon to mouse liver glycogen (14).

The present investigation was undertaken to study the mechanism of nucleic acid ribose synthesis by a human carcinoma cell (strain HeLa) grown in tissue culture. The results are consistent with ribose production via both the oxidative and nonoxidative steps of the pentose phosphate pathway, with the nonoxidative route predominating.

\section{METHODS}

Tissue culture. A human carcinoma cell (strain HeLa) and a human liver cell (Henle, strain 407) were grown in the amino acid-vitamin-salt-glucose medium described by Eagle (15) supplemented with 5 per cent whole horse serum. After two or three days of incubation, at which time the inoculated cells were firmly adherent to the wall of the 1-liter Blake bottle in which they were grown, the $\mathrm{C}^{16}$-labeled substrate was added in the amount described. The medium was renewed every second or third

1 These studies were supported by grants from the Jane Coffin Childs Memorial Fund for Medical Research and from the National Cancer Institute, United States Public Health Service (C 2673), and, in part, by an American Cancer Society grant to Harvard University. day, together with additional radioactive substrate. The period of growth varied from 7 to 14 days. The radioactive compounds in the amounts employed had no discernible effect on cellular morphology or on rate of growth. At the termination of the growth period the cells were scraped from the wall of the bottle with a rubber policeman into $5 \mathrm{ml}$. of cold 10 per cent trichloroacetic acid (TCA).

Isolation of ribose. The ribonucleotides were isolated by a modification (16) of the procedure of Schmidt and Thannhauser (17). The harvested HeLa cells were homogenized for two minutes in a Potter-Elvehjem teflon homogenizer in 10 per cent TCA at $0^{\circ} \mathrm{C}$. After centrifugation the precipitate was washed with $5 \mathrm{ml}$. of cold 5 per cent TCA. The precipitate was then extracted consecutively with $8 \mathrm{ml}$. of cold ethanol, $8 \mathrm{ml}$. of ethanol at $25^{\circ} \mathrm{C}$., and twice with $8 \mathrm{ml}$. of an ethanol: ether $(3: 1)$ mixture. The cellular residue with $5 \mathrm{mg}$. each of ribonucleic acid and of deoxyribonucleic acid as carrier was then extracted with $1 \mathrm{ml}$. of 10 per cent sodium chloride in a boiling water bath for 20 minutes. After centrifugation the residue was similarly extracted twice with $0.5 \mathrm{ml}$. of 10 per cent sodium chloride for 20 minutes. To the combined extracts two volumes of ethanol were added. This mixture was kept at $5^{\circ} \mathrm{C}$. overnight. The white precipitate was centrifuged, washed with $1 \mathrm{ml}$. of cold ethanol and with $1 \mathrm{ml}$. of ether, and then dried in air. One $\mathrm{ml}$. of $1 \mathrm{~N} \mathrm{KOH}$ was added and the mixture incubated at $30^{\circ} \mathrm{C}$. for 22 hours. Deoxyribonucleic acid was precipitated by acidification with sufficient $\mathrm{H}_{2} \mathrm{SO}_{4}$ to make a final concentration of $0.5 \mathrm{~N}$, and removed by centrifugation. Dephosphorylation of the ribonucleotides, which remained in the supernatant solution, was carried out by adjusting the $\mathrm{pH}$ to 5.6 , adding acetate buffer to make a final concentration of $0.15 \mathrm{M}$, and introducing $0.1 \mathrm{ml}$. of acid phosphatase (Worthington wheat germ phosphatase, $20 \mathrm{mg}$. per ml. of water). The mixture was incubated at $30^{\circ} \mathrm{C}$. for two hours, and the reaction stopped by placing the tube in boiling water for two minutes. The $\mathrm{pH}$ of the solution was then adjusted to 6.0 with $\mathrm{KOH}$. The nucleosides were hydrolyzed by incubation with $1 \mathrm{ml}$. of riboside hydrolase (18) at $34^{\circ} \mathrm{C}$. for three hours. The reaction was stopped in boiling water, and the solution centrifuged. The supernatant solution was deionized by passage through a mixed bed resin (MB-3; Fisher Scientific Company). The effluent was lyophilized to dryness and the residue taken up in methanol. The methanol solution was streaked on Whatman No. 1 paper and the 
ribose purified by descending chromatography in N-butanol-glacial acetic acid-water $(4: 1: 5)$ for 20 hours (19). A standard ribose solution was spotted on the paper lateral to both margins of the HeLa cell mixture. The position of the ribose was located by streaking with aniline phthalate reagent $(20)$ the area of the paper over which the standard ribose solution had migrated and the adjacent margins of the incubation mixture. The strip containing the ribose was cut out and the sugar eluted with water.

Degradation of ribose. The RNA ribose, to which was added sufficient unlabeled ribose to make a total of 350 $\mu \mathrm{M}$, was degraded to acetate (carbons 1 and 2 of ribose) and lactate (carbons 3, 4, and 5) by fermentation with Lactobacillus pentosus (21). The fermentation products were isolated as described by Bernstein (22). Acetate was converted to barium carbonate $\left(\mathrm{BaCO}_{2}\right)$ in stepwise fashion as described by Phares (23). Lactate was degraded to $\mathrm{CO}_{2}$ (carbon 3 of ribose) and acetate (carbons 4 and 5) by the method of Aronoff, Haas, and Fries (24), and the acetate was subjected to the Phares procedure (23). The microbiological and chemical degradation techniques permitted the isolation of each carbon atom of the ribose molecule as $\mathrm{BaCO}_{2}$. When ribose-1- $\mathrm{C}^{26}$ was degraded in this fashion, over 99 per cent of the total radioactivity was found in carbon 1 .

Determination of radioactivity. Bicarbonate- $\mathrm{C}^{\mathrm{4}}$, the radioactive sugars, and the cellular extracts were counted at "infinite" thinness with a gas flow counter, operating at an efficiency of 40 per cent. $\mathrm{BaC}^{14} \mathrm{O}_{8}$ was counted at "infinite" thickness. All determinations were continued sufficiently long so as to reduce the counting error to less than 3 per cent.

Chemical and enzymatic procedures. Phosphate was determined by the method of Taussky and Shorr (25), and ribose by a modification (26) of the Mejbaum procedure (27). Riboside hydrolase was prepared from Lactobacillus delbruckii, according to the method of Takagi and Horecker (18). The activity of the preparation was assayed with inosine as substrate and xanthine oxidase, kindly provided by Dr. Boris Magasanik.

Materials. The initial stock cultures of $\mathrm{HeLa}$ cell and of a liver cell were generously provided by Dr. George Foley.

Bicarbonate- $\mathrm{C}^{16}$ was prepared by absorbing in $\mathrm{NaOH}$ $\mathrm{C}^{14} \mathrm{O}_{2}$ liberated from $\mathrm{BaC}^{14} \mathrm{O}_{3}$, and then neutralizing to the phenolphthalein end point. Glucose-1- $C^{16}$ was purchased from Nuclear Chemical and Instrument Corporation, and glucose-2- $\mathrm{C}^{16}$ and ribose-1- $\mathrm{C}^{16}$ from the National Bureau of Standards. The glucose substrates were degraded as described previously (14) and the ribose-1- $\mathrm{C}^{\mathbf{1 4}}$ by Lactobacillus pentosus fermentation in order to verify isotope distribution.

\section{RESULTS}

\section{Incorporation of radioactive substrates}

All of the $\mathrm{C}^{14}$-substrates were incorporated into HeLa cell (Table I). Since the rate and amount of cell growth varied considerably from one study to another, quantitative conclusions cannot be drawn from the incorporation data. Radioactivity was distributed in several cellular extracts (Table I). When carrier glycogen was added to the cold TCA extract of HeLa cell grown in the presence of bicarbonate- $\mathrm{C}^{14}$ and the glycogen then recrystallized, no radioactivity was detected. In similar fashion, no glycogen formation could be detected in the human liver cell grown in tissue culture in the presence of $\mathrm{NaHC}^{14} \mathrm{O}_{3}$.

\section{Isotope distribution in $R N A$ ribose (Table II)}

The ribose from cells grown in the presence of uniformly labeled glucose was also uniformly labeled. (This sample of ribose was isolated and kindly provided by Drs. B. L. Horecker and $\mathrm{H}$. Eagle.) Ribose derived from glucose-1-C $\mathrm{C}^{14}$ was predominantly labeled in carbon 1 with somewhat

TABLE I

Distribution of $C^{14}$ in HeLa cell grown in presence of $C^{14}$-substrates

\begin{tabular}{|c|c|c|c|c|c|c|}
\hline \multirow[b]{2}{*}{$\begin{array}{l}\text { Experiment } \\
\text { number }\end{array}$} & \multirow[b]{2}{*}{ 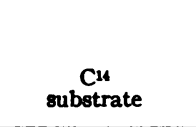 } & \multirow[b]{2}{*}{$\begin{array}{l}\text { Total } \mu c . \\
\text { added }\end{array}$} & \multirow[b]{2}{*}{$\begin{array}{l}\text { Incubation } \\
\text { period } \\
\text { (days) }\end{array}$} & \multicolumn{3}{|c|}{ Total c.p.m. in cell extracts } \\
\hline & & & & $\begin{array}{l}\text { Cold TCA } \\
\text { soluble }\end{array}$ & $\begin{array}{l}\text { Alcohol and } \\
\text { alcohol-ether } \\
\text { soluble }\end{array}$ & Nucleotides \\
\hline $\begin{array}{r}3 \\
11 \\
12 \\
31 \\
38 \\
39 \\
41 \\
43 \\
44 \\
42\end{array}$ & 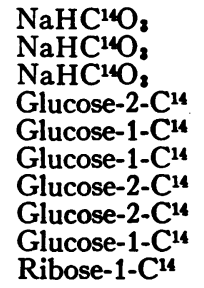 & $\begin{array}{l}470 \\
430 \\
200 \\
14.8 \\
11 \\
22 \\
13 \\
13 \\
11 \\
10\end{array}$ & $\begin{array}{r}10 \\
19 \\
7 \\
6 \\
6 \\
10 \\
10 \\
6 \\
6 \\
4\end{array}$ & $\begin{array}{l}28,000 \\
75,700 \\
35,200 \\
18,900 \\
18,000 \\
12,200 \\
12,100 \\
15,800 \\
18,500 \\
10,400\end{array}$ & $\begin{array}{r}6,600 \\
7,600 \\
21,000 \\
68,000 \\
43,000 \\
52,000 \\
23,000 \\
38,000 \\
20,000 \\
19,500\end{array}$ & $\begin{array}{r}21,000 \\
27,000 \\
14,700 \\
27,000 \\
13,800 \\
59,200 \\
8,650 \\
21,900 \\
25,900 \\
39,700\end{array}$ \\
\hline
\end{tabular}


TABLE II

$C^{14}$ distribution in $R N A$ ribose of HeLa cell grown in medium containing $C^{14}$-substrate

\begin{tabular}{|c|c|c|c|c|c|c|}
\hline \multirow{2}{*}{$\begin{array}{l}\text { Experiment } \\
\text { number }\end{array}$} & \multirow{2}{*}{$\underset{\text { substrate }}{\mathrm{Cu}}$} & \multicolumn{5}{|c|}{ Per cent total activity* } \\
\hline & & C-1 & $\mathrm{C}-2$ & $\mathrm{C}_{3} 3$ & $\mathrm{C}-4$ & C.5 \\
\hline 1 & Glucose-U-C ${ }^{14}$ & 19.9 & 20.1 & 20.0 & 20.0 & 20.0 \\
\hline 39 & Glucose-1-C 14 & $\begin{array}{l}52.8 \\
(655)\end{array}$ & $\begin{array}{r}(02.1) \\
4.9\end{array}$ & 8.2 & 0.5 & 33.6 \\
\hline 44 & Glucose-1-C ${ }^{14}$ & 47.8 & 4.2 & 8.0 & 2.8 & 37.2 \\
\hline 31 & Glucose-2-C ${ }^{14}$ & $\begin{array}{c}(0.99) \\
22.6\end{array}$ & $\begin{array}{c}38.7 \\
(1.76)\end{array}$ & 9.9 & 26.0 & 2.8 \\
\hline 43 & Glucose-2-C & 23.3 & $\begin{array}{r}37.0 \\
(0.37)\end{array}$ & 11.6 & 22.3 & 5.8 \\
\hline 42 & Ribose-1-C ${ }^{14}$ & $\begin{array}{c}74.0 \\
(5.80)\end{array}$ & 3.9 & 9.8 & 1.9 & 10.4 \\
\hline
\end{tabular}

* The specific activity (in millimicrocuries per millimole of carbon) of the most radioactive carbon atom is given in_parentheses.

less activity in carbon 5. The major sites of isotope localization in ribose synthesized from glucose-2- $\mathrm{C}^{14}$ were positions 2,1 , and 4 , with the latter two carbon atoms less active than the former. Ribose from cells grown in the presence of ribose-1-C $\mathrm{C}^{14}$ was most heavily labeled in carbon 1 , but some randomization of isotope had taken place, particularly to carbons 3 and 5 .
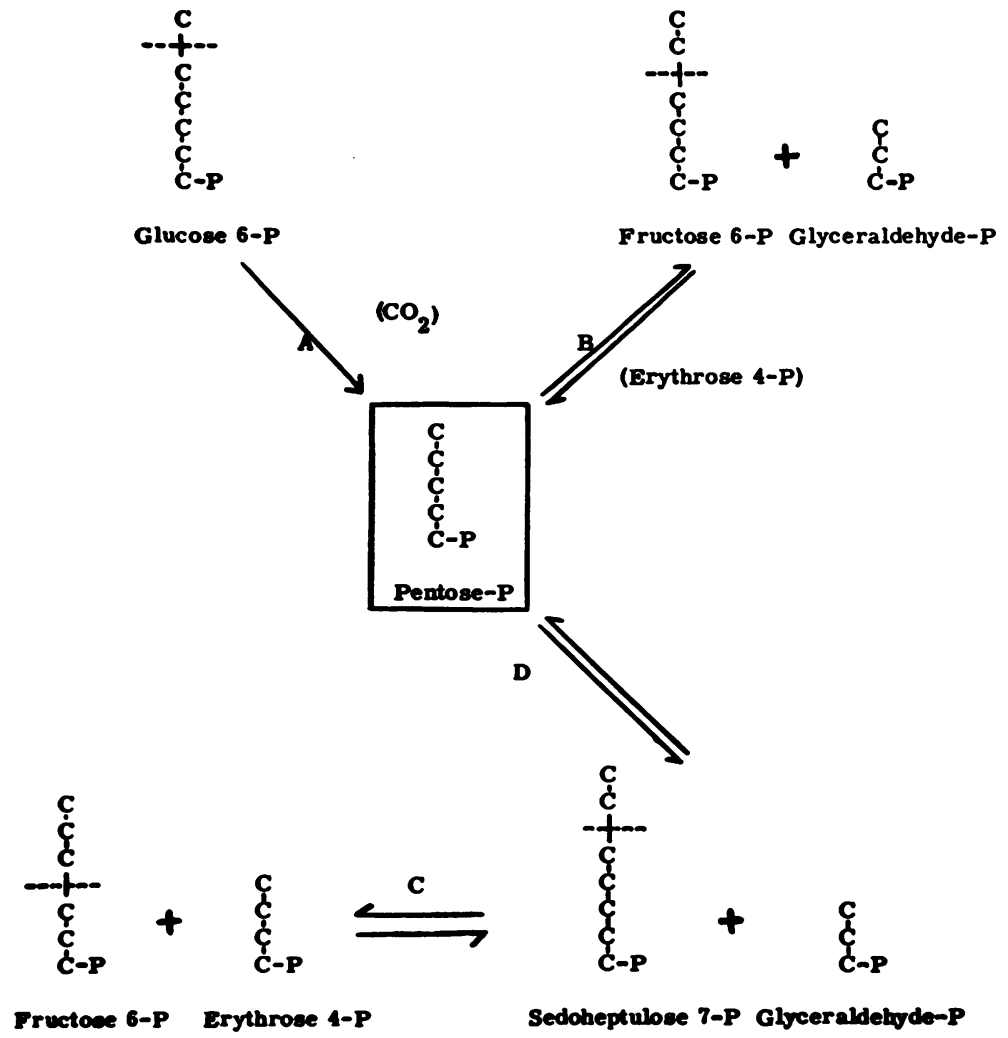

Fig. 1. Pentose Phosphate Synthesis Via the Oxidative (A) and Nonoxidative Steps (B, C, D) of the Pentose Phosphate Pathway

The compounds in parentheses (steps $A$ and $B$ ) are the reaction products other than pentose phosphate. 


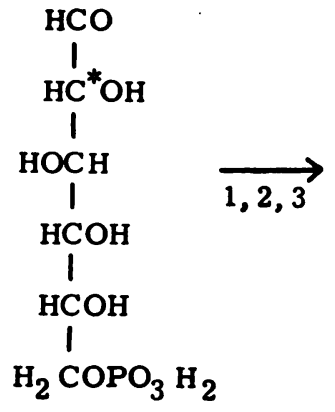

Glucose 6-P

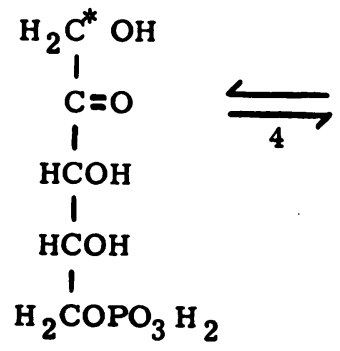

Ribulose 5-P

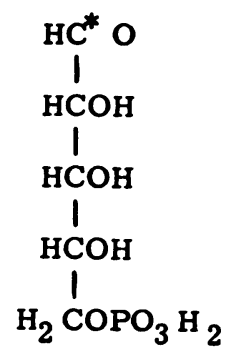

Ribose 5-P

1. Glucose 6-P dehydrogenase

2. Lactonase

3. 6-P gluconic dehydrogenase

4. Pentose phosphate isomerase

Fig. 2. Production of Ribose-1-C Phosphate by Oxidative Removal of Carbon 1 of Glucose-2-C $C^{16}$ Phosphate

$\mathrm{C}^{16}$ is indicated by the asterisk.

To exclude the possibility that the RNA ribose may have been contaminated by ribose-1- $\mathrm{C}^{14}$ substrate, $4 \mu \mathrm{c}$. of ribose-1- $\mathrm{C}^{14}$ were added to $\mathrm{HeLa}$ cells grown in the absence of $\mathrm{C}^{14}$ and treated with TCA. The nucleotide fraction isolated following the steps outlined above was found to be free of radioactivity.

\section{DISCUSSION}

Pentose phosphate may be generated by both oxidative and nonoxidative reactions of the pen- tose phosphate pathway (28) (Figure 1). In the oxidative steps carbon 1 of glucose 6-phosphate is converted to $\mathrm{CO}_{2}$ and carbon atoms 2 to 5 to ribulose phosphate (Figures 1 (A) and 2). The nonoxidative reactions are described in Figures 1 (B, $\mathrm{C}$, and $\mathrm{D}), 3$, and 4 . One nonoxidative reaction involves the transfer of the first two carbon atoms of a molecule of fructose 6-phosphate to an appropriate acceptor, such as glyceraldehyde phosphate (Figures 1(B) and 3) (29). This reaction is catalyzed by the enzyme, transketolase (30),

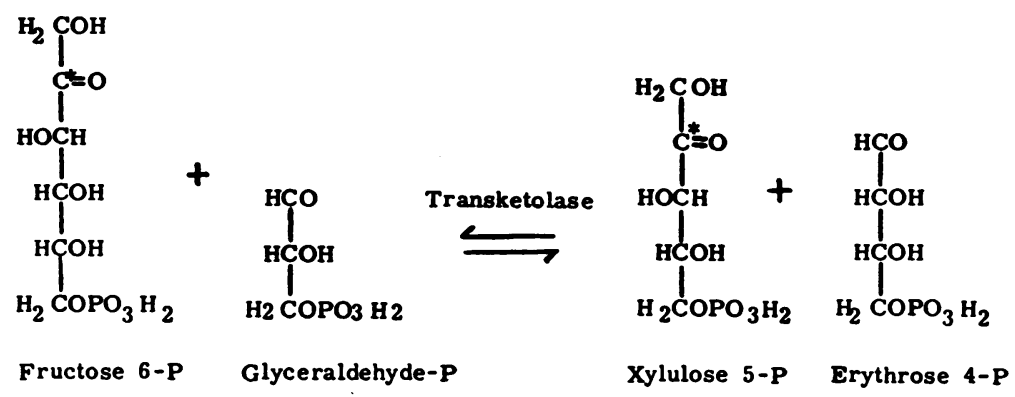

Fig. 3. Production of Xylulose-2-C ${ }^{14}$ Phosphate from Hexose-2-C ${ }^{14}$ Phosphate by Transfer of the First Two Carbons of Hexose to Glyceraldehyde Phosphate

The other product of this reaction, erythrose-4-phosphate, which is derived from carbons 3 to 6 of hexose, may then participate in the reactions shown in Figure 4. 

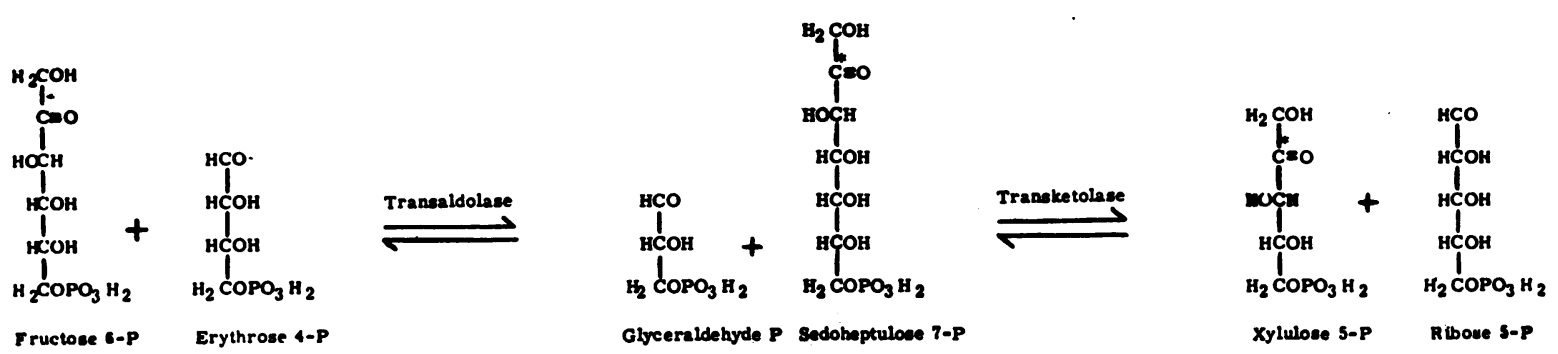

Fig. 4. Production of Xylulose-2-C ${ }^{16}$ Phosphate and Ribose Phosphate from Hexose-2-C ${ }^{16}$ Phosphate and Erythrose Phosphate

In the transaldolase reaction the first three carbons of hexose are transferred to erythrose, resulting in the formation of a 7-carbon sugar phosphate, sedoheptulose-2- $\mathrm{C}^{14}$, and glyceraldehyde phosphate. The first two carbons of sedoheptulose are then cleaved in the transketolase reaction, and condense with triose to form a molecule of xylulose$2-\mathrm{C}^{14}$ phosphate, leaving a molecule of unlabeled ribose phosphate.

and the products are a molecule of pentose phosphate, xylulose 5-phosphate, and one of a 4-carbon sugar phosphate, erythrose 4-phosphate. The erythrose 4-phosphate may then act as acceptor for a 3-carbon unit cleaved from a second molecule of fructose 6-phosphate under the influence of transaldolase (Figures 1 (C) and 4) (31). The products of this reaction are a molecule of a 7-carbon sugar phosphate, sedoheptulose 7-phosphate, and one of triose phosphate. Transketolase may then mediate the transfer of the first two carbons of sedoheptulose phosphate to triose phosphate, yielding two molecules of pentose phosphate, one of xylulose 5-phosphate $(32,33)$ and one of ribose 5-phosphate (Figures 1 (D) and 4). To summarize these reactions (Figure 1 ), the oxidative steps in the pathway mediate the conversion of a molecule of hexose phosphate to one each of pentose phosphate and of $\mathrm{CO}_{2}$. The transketolasetransaldolase reactions, on the other hand, catalyze the conversion of two molecules of hexose phosphate and one of glyceraldehyde phosphate to three molecules of pentose phosphate. All of the nonoxidative reactions in the pentose phosphate pathway are reversible, so that hexose monophosphate may be generated from pentose phosphate.

The enzymes responsible for the interconversion of the three pentose phosphates, xylulose, ribulose, and ribose, which arise in these reactions (Figure 5) are widespread in nature (34). Hence, both of the ketopentose esters, ribulose and xylulose, may be converted to ribose 5-phosphate. It is the latter which is involved in nucleotide synthesis (35).

Examination of the isotope distribution in $\mathrm{HeLa}$ cell ribose permits a recapitulation of the reactions by which the pentose was synthesized. If $\mathrm{HeLa}$ cell ribose were generated via oxidative loss of carbon 1 of hexose phosphate (Figure 2), the pentose derived from glucose-1-C $\mathrm{C}^{14}$ would be unlabeled, and that obtained from glucose-2-C $\mathrm{C}^{14}$ would be labeled in carbon 1 . On the other hand, if the major pathway of ribose production involved the transketolase-transaldolase reactions, then carbons 1 and 2 of ribose would be derived from carbons 1 and 2 of hexose (Figures 3 and 4 ). Thus, ribose synthesized via the nonoxidative sequence of reactions from glucose-1- $\mathrm{C}^{14}$ would be
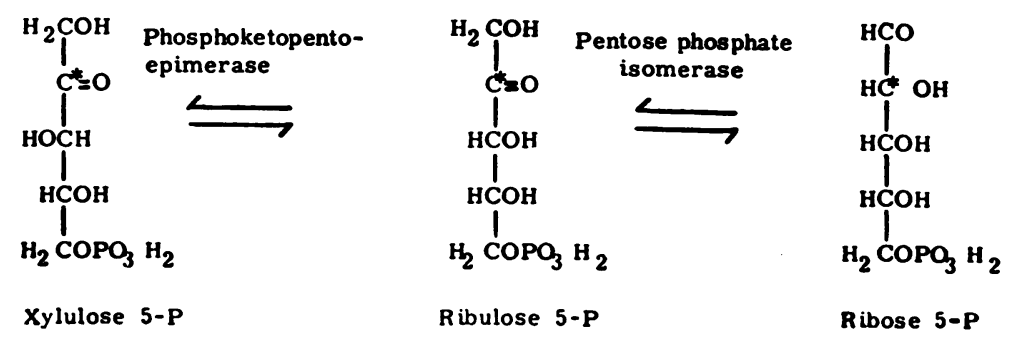

Fig. 5. Interconversion of the Three Pentose Phosphates Involved in the Pentose Phosphate Pathway 
(a)

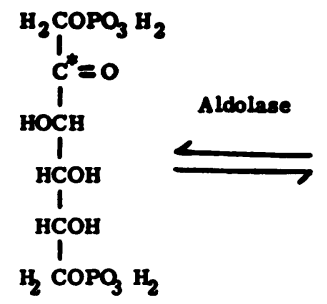

Hexose di-P
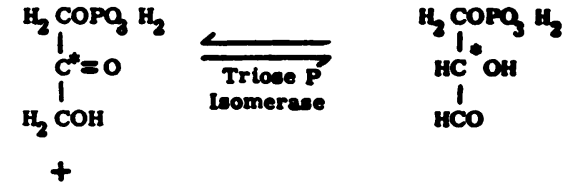

нсо

1

$\mathrm{H}_{2} \mathrm{COPO}_{3} \mathrm{H}_{2}$

Dihydroxyacetone $P$
+
Glycersidehyde $P$

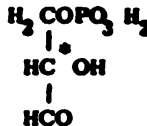

Glyceraldehyde P

(b)
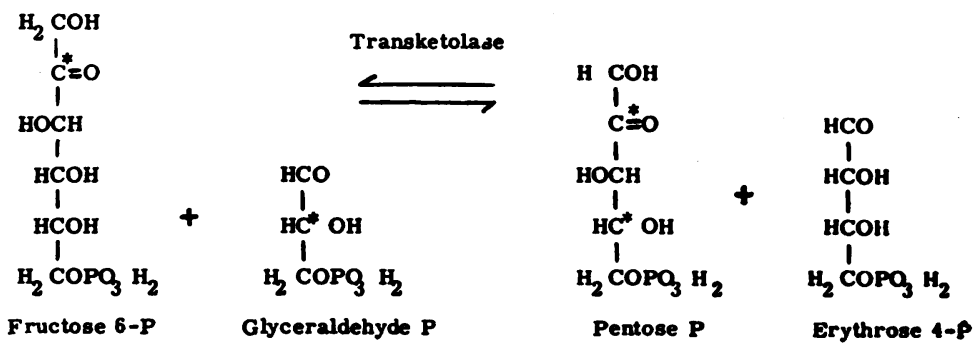

Fig. 6. (a) Production of Glyceraldehyde-2-C ${ }^{36}$ Phosphate From Hexose-2-C Dip Diposphate Via the Aldolase and Isomerase Reactions (b) Production of Pentose-4-C $C^{14}$ Phosphate From Glyceraldehyde-2-C $C^{\text {b }}$ Phosphate in the Transketolase Reaction

Isotope in carbon 2 of the two-carbon donor in this reaction, e.g., fructose2-C ${ }^{14}$ phosphate, would, of course, appear in carbon 2 of the pentose phosphate.

labeled in position 1 , and that obtained from glucose-2- $\mathrm{C}^{14}$ would have isotope in position 2 . In the studies in which glucose-2-C $\mathrm{C}^{14}$ was the HeLa cell substrate considerable radioactivity was found in both positions 1 and 2 of ribose. Therefore, both oxidative removal of the first carbon of hexose phosphate and the nonoxidative reactions may be presumed to have been operative in ribose production. The fact that ribose obtained from glucose-2- $\mathrm{C}^{14}$ had 50 per cent more activity in position 2 than in 1 suggests that the nonoxidative reactions are the predominant route of ribose synthesis in HeLa cell. No quantitative conclusions concerning the relative roles of the oxidative and nonoxidative series of reactions can be drawn from the studies with glucose-1-C ${ }^{14}$. In these experiments only the participation of the transketolase reaction would be reflected in the isotope distribution in ribose, for any pentose synthesized via loss of carbon 1 of glucose-1-C ${ }^{14}$ would, of course, be unlabeled. Ribose synthesized via the transketolase reaction, however, would be labeled in carbon 1 .
The participation of both oxidative and nonoxidative steps of the pentose phosphate pathway in ribose synthesis by $\mathrm{HeLa}$ cell is similar to reported mechanisms of nucleic acid ribose production in vivo by rat liver $(9,10)$ and of synthesis of the ribityl moiety of riboflavin in Ashbya gossyppie (7). Ribose synthesis by Escherichia coli $(5,8)$ and by Torula utilis $(6)$, on the other hand, occurs mainly via oxidative loss of carbon 1 of glucose phosphate, while in the chick little pentose is produced by this means (4).

The substantial radioactivity in carbon 4 of ribose derived from glucose-2-C $\mathrm{C}^{14}$ and in carbon 5 of ribose synthesized from glucose-1- $\mathrm{C}^{14}$ is consistent with the intense glycolytic activity of tumor cells $(36,37)$. As a result of aldolase cleavage of hexose diphosphate and isomerization of the triose phosphates, glucose-1- $\mathrm{C}^{14}$ and glucose$2-C^{14}$ would give rise to glyceraldehyde phosphate labeled in positions 3 and 2, respectively [Figure $6(a)]$. The condensation of a two-carbon fragment with triose-2- $\mathrm{C}^{14}$ phosphate in the transketolase reaction would give rise to ribose with isotope 
in carbon 4 [Figure 6(a)], while by the same mechanism radioactivity in position 3 of triose phosphate would appear in carbon 5 of ribose. Similar isotope distribution apparently via the aldolase reaction has been observed in the ribityl portion of riboflavin synthesized by Ashbya gossyppie (7).

Ribose has been shown to support the growth of HeLa cell in the absence of glucose (38). Our studies, in which glucose was the principal carbohydrate source and ribose-1-C $\mathrm{C}^{\mathbf{1 4}}$ was added in tracer quantity, suggest that considerable ribose is incorporated directly into nucleotide, rather than following prior conversion to hexose. Ribose$1-C^{14}$ has been shown to be converted to hexose$1,3-C^{14}$, both in vitro (39) and in the mouse in vivo (14). If such a prior reaction had taken place to an appreciable extent in our system, then some ribose would have been synthesized from the oxidative loss of carbon 1 of glucose-1,3-C ${ }^{14}$ and would have been labeled in position 2. Further, aldolase cleavage of hexose-1,3-C $\mathrm{C}^{14}$ would have given rise to triose-1,3-C ${ }^{14}$. Condensation of a 2 carbon fragment in the transketolase reaction with triose-1,3-C14 would have resulted in radioactivity in positions 3 and 5 of ribose (Figure 6). The appearance of a relatively small concentration of isotope in those sites, particularly in positions 3 and 5 (Table II), suggests that some ribose-to-hexose conversion may have preceded ribose incorporation into nucleotide. The marked predominance of isotope in carbon 1 , however, indicates that the major fraction of ribose- $\mathrm{C}^{14}$ was incorporated unchanged into nucleotide.

From our studies one cannot determine whether ribose is incorporated directly into nucleotide following its synthesis by HeLa cell. If incorporation is not direct, exchange reactions, as well as ribose to hexose to ribose recycling, could take place, and isotope distribution would thereby be altered. As a result, the pattern of radioactivity in the ribose molecule would reflect not only the reactions involved in net synthesis, but also those participating in exchange and recycling. From the experiment with ribose-1- $\mathrm{C}^{14}$ one may conclude that ribose to hexose to ribose recycling does not take place to a sufficient extent to alter markedly the isotope pattern in RNA ribose synthesized by HeLa cell under the conditions of our experiments. The effect of exchange reactions on iso- tope distribution, however, cannot be ascertained from our data. For example, exchange via the transketolase reaction of the first two carbons of a molecule of hexose-2-C $\mathrm{C}^{14}$ phosphate with the first two carbons of a molecule of unlabeled pentose phosphate, would give rise to a molecule of pen-

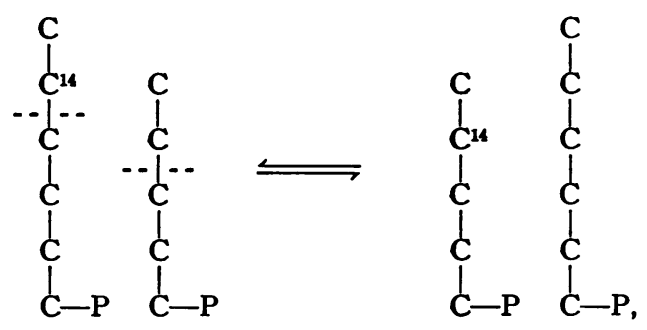

tose-2- $\mathrm{C}^{14}$ phosphate without any net synthesis having taken place. Experiments now in progress suggest that such alterations in the pentose molecule do not occur to a significant extent as compared with isotope movement resulting from net synthetic reactions.

\section{SUMMARY}

Nucleic acid ribose has been isolated from a human carcinoma cell (strain HeLa) grown in an amino acid-vitamin-salt-glucose medium containing $\mathrm{C}^{14}$-labeled substrates. Isotope distribution in the ribose is consistent with its synthesis via both oxidative and nonoxidative steps of the pentose phosphate pathway. The nonoxidative mechanism appears to predominate. No glycogen synthesis was detected in HeLa cell or in a liver cell grown in tissue culture.

\section{ACKNOWLEDGMENTS}

The valuable assistance of Misses Jacqueline Lareau and Arlene Guenzel is gratefully acknowledged. The generous advice and help of Dr. George Foley greatly assisted in the establishment of the tissue culture program.

\section{REFERENCES}

1. Horecker, B. L., and Mehler, A. H., Carbohydrate metabolism. Ann. Rev. Biochem., 1955, 24, 207.

2. Bassham, J. A., Benson, A. A., Kay, L. D., Harris, A. Z., Wilson, A. T., and Calvin, M., The path of carbon in photosynthesis. XXI. The cyclic regeneration of carbon dioxide acceptor. J. Am. Chem. Soc., 1954, 76, 1760.

3. Gunsalus, I. C., Horecker, B. L., and Wood, W. A., Pathways of carbohydrate metabolism in microorganisms. Bact. Rev., 1955, 19, 79. 
4. Bernstein, I. A., Synthesis of ribose by the chick. J. Biol. Chem., 1953, 205, 317.

5. Lanning, M. C., and Cohen, S. S., The mechanism of ribose formation in Escherichia coli. J. Biol. Chem., 1954, 207, 193.

6. Sowden, J. C., Frankel, S., Moore, B. H., and McClary, J. E., Utilization of 1-C14-D-glucose by Torula utilis yeast. J. Biol. Chem., 1954, 206, 547.

7. Plaut, G. W. E., and Broberg, P. L., Biosynthesis of riboflavin. III. Incorporation of $\mathrm{C}^{14}$-labeled compounds into the ribityl side chain. J. Biol. Chem., 1956, 219, 131.

8. Bernstein, I. A., Biosynthesis of ribose in Escherichia coli grown on $\mathrm{C}^{14}$-labeled glucose. J. Biol. Chem., 1956, 221, 873.

9. Bernstein, I. A., Synthesis of ribose by the rat. Biochim. et biophys. acta, 1956, 19, 179.

10. Marks, P. A., and Feigelson, P., The biosynthesis of nucleic acid ribose and of glycogen glucose in the rat. J. Biol. Chem., 1957, 226, 1001.

11. Srinivasan, P. R., Shigeura, H. T., Sprecher, M., Sprinson, D. B., and Davis, B. D., The biosynthesis of shikimic acid from D-glucose. J. Biol. Chem., 1956, 220, 477.

12. Siperstein, M. D., and Fagan, V. M., The role of glucose oxidation in the synthesis of cholesterol and fatty acids (abstract). J. Clin. Invest., 1957, 36, 929.

13. Bloom, B., and Stetten, D., Jr., Pathways of glucose catabolism. J. Am. Chem. Soc., 1953, 75, 5446.

14. Hiatt, H. H., Glycogen formation via the pentose phosphate pathway in mice in vivo. J. Biol. Chem., 1957, 224, 851.

15. Eagle, H., The specific amino acid requirements of a human carcinoma cell (strain $\mathrm{HeLa}$ ) in tissue culture. J. Exper. Med., 1955, 102, 37.

16. Takagi, Y., Personal communication.

17. Schmidt, G., and Thannhauser, S. J., A method for the determination of desoxyribonucleic acid, ribonucleic acid, and phosphoproteins in animal tissues. J. Biol. Chem., 1945, 161, 83.

18. Takagi, Y., and Horecker, B. L., Purification and properties of a bacterial riboside hydrolase. J. Biol. Chem., 1957, 225, 77.

19. Partridge, S. M., Filter-paper partition chromatography of sugars. Biochem. J., 1948, 42, 238.

20. Partridge, S. M., Aniline hydrogen phthalate as a spraying reagent for chromatography of sugars. Nature, 1949, 164, 443.

21. Gest, H., and Lampen, J. O., Fermentaton of 1-C16-Dxylose by Lactobacillus pentosus. J. Biol. Chem,. 1952, 194, 555.

22. Bernstein, I. A., Fermentation of ribose-C $C^{16}$ by Lactobacillus pentosus. J. Biol. Chem., 1953, 205, 309.
23. Phares, E. F., Degradation of labeled propionic and acetic acids. Arch. Biochem. \& Biophys., 1951, 33, 173.

24. Aronoff, S., Haas, A., and Fries, B. A., Degradation of isotopic lactate and acetate. Atomic Energy Commission Document-1832, 1948.

25. Taussky, H. H., and Shorr, E., A microcolorimetric method for the determination of inorganic phosphorus. J. Biol. Chem., 1953, 202, 675.

26. Albaum, H. G., and Umbreit, W. W., Differentiation between ribose-3-phosphate and ribose-5-phosphate by means of the orcinol-pentose reaction. J. Biol. Chem., 1947, 167, 369.

27. Mejbaum, W., Uber die Bestimmung kleiner Pentosemengen, insbesondere in Derivaten der Adenylsäure. Ztschr. f. physiol. Chem., 1939, 258, 117.

28. Horecker, B. L., A new pathway for the oxidation of carbohydrate. The Brewers' Digest, 1953, 28, 214.

29. Racker, E., de la Haba, G., and Leder, I. G., Transketolase-catalyzed utilization of fructose 6-phosphate and its significance in a glucose 6-phosphate oxidation cycle. Arch. Biochem. \& Biophys., 1954, 48, 238.

30. Horecker, B. L., Smyrniotis, P. Z., and Klenow, H., The formation of sedoheptulose phosphate from pentose phosphate. J. Biol. Chem., 1953, 205, 661.

31. Horecker, B. L., and Smyrniotis, P. Z., Transaldolase : The formation of fructose 6-phosphate from sedoheptulose 7-phosphate. J. Am. Chem. Soc., 1953, 75, 2021.

32. Srere, P. A., Cooper, J. R., Klybas, V., and Racker, E., Xylulose 5-phosphate, a new intermediate in the pentose phosphate cycle. Arch. Biochem. \& Biophys., 1955, 59, 535.

33. Horecker, B. L., Hurwitz, J., and Smyrniotis, P. Z., Xylulose 5-phosphate and the formation of sedoheptulose 7-phosphate with liver transketolase. J. Am. Chem. Soc., 1956, 78, 692.

34. Dickens, F., and Williamson, D. H., Pentose phosphate isomerase and epimerase from animal tissues. Biochem. J., 1956, 64, 567.

35. Kornberg, A., Lieberman, I., and Simms, E. S., Enzymatic synthesis and properties of 5-phosphoribosylpyrophosphate. J. Biol. Chem., 1955, 215, 389.

36. Warburg, O., The Metabolism of Tumors. London, Constable \& Co., 1930.

37. Hiatt, H. H., Glycolytic activity in vivo of the mouse Ehrlich ascites tumor. Cancer Research, 1957, 17, 240.

38. Eagle, H., Personal communication.

39. Horecker, B. L., Gibbs, M., Klenow, H., and Smyrniotis, P. Z., The mechanism of pentose phosphate conversion to hexose monophosphate. I. With a liver enzyme preparation. J. Biol. Chem., 1954, 207, 393. 